\title{
Evaluation of glycerylphosphocholine in semen of normal and infertile men
}

\author{
S. P. Sane, K. L. Patel, K. B. O. Pillai and S. M. Shahani \\ Department of Endocrinology, T. N. Medical College and B. Y. L. Nair Hospital, \\ Bombay 400 008, India
}

\begin{abstract}
Summary. Glycerylphosphocholine (GPC) concentration varied directly with sperm density and percentage motility. In astheno-normospermic semen samples, the GPC concentration was significantly lower than in normal samples.
\end{abstract}

\section{Introduction}

Glycerylphosphocholine (GPC), an important constituent of human seminal plasma (Dawson, Mann \& White, 1957; Dawson \& Rowlands, 1959), is secreted mainly by the epididymal epithelium (Wallace, Wales \& White, 1966; Calamera \& Lavieri, 1974; Frenkel, Peterson, Davis \& Freund, 1974) and under androgenic control (Dawson \& Rowlands, 1959). It is present in high concentrations in the epididymis of many mammalian species (Dawson \& Rowlands, 1959; Scott, Wales, Wallace \& White, 1963; Wallace et al., 1966) as compared to man (Dawson et al., 1957).

The physiological role of GPC in semen is still unknown. The present study was initiated with the objective of evaluating its role in fertility by correlating the GPC levels in human seminal plasma with sperm count and percentage motility.

\section{Materials and Methods}

Infertile males attending the endocrine infertility clinic of this hospital and normal healthy volunteers were selected as subjects for the present study. Semen samples were obtained by masturbation into clean sterile bottles after an abstinence of 3-4 days.

The semen samples were analysed, after allowing for complete liquefaction, for sperm count and percentage sperm motility by standard procedures (Eliasson, 1971). Motility was assessed 1 $\mathrm{h}$ after collection on the basis of vitality as determined by a supravital stain on seminal smears (Eliasson, 1971). Samples were grouped as (1) azoospermic (no spermatozoa), (2) necrospermic (all spermatozoa non-motile), (3) astheno-normospermic (count $>40 \times 10^{6} / \mathrm{ml}$ with motility $<20 \%$ ), and (4) normospermic (count $>40 \times 10^{6} / \mathrm{ml}$ with motility $>40 \%$ ).

Semen samples were then centrifuged at $1000 \mathrm{~g}$ for $30 \mathrm{~min}$ at $5^{\circ} \mathrm{C}$ and the supernatant plasma was separated and preserved at $-20^{\circ} \mathrm{C}$ until analysed for its GPC content by the method of White (1959). The method involves: (1) removal of fructose by copper-lime treatment, (2) oxidation of glycerol to formaldehyde by periodate and the excess periodate destroyed by arsenite, and (3) colorimetric estimation of formaldehyde by formation of a coloured complex with a chromotropic acid reagent.

The results were expressed as mean \pm s.e.m. and were analysed for statistical significance by Student's $t$ test. Correlation coefficients between GPC concentration and sperm count and percentage of motility were also evaluated. 


\section{Results}

The GPC concentrations in relation to sperm density and sperm motility are shown in Table 1 . The GPC concentration varied directly with the increase in sperm density and percentage motility. The levels of GPC were significantly higher in normospermic and even oligospermic samples when compared with azoospermic samples $(r=0.3, P<0.001)$. Only semen samples with $40 \%$ motility had GPC concentrations different from those with necrospermia $(r=0.22, P$ $<0.01$ ). The correlation coefficient between GPC concentration and percentage motility of spermatozoa in normospermic and astheno-normospermic samples was significant $(r=0 \cdot 27, P$ $<0.05$ : Table 2).

Table 1. Glycerylphosphocholine (GPC) concentrations in relation to sperm density and sperm motility

\begin{tabular}{ccc|ccc}
\hline $\begin{array}{c}\text { Sperm density } \\
\left(10^{6} / \mathrm{ml}\right)\end{array}$ & $\begin{array}{c}\text { No. of } \\
\text { men }\end{array}$ & $\begin{array}{c}\text { GPC } \\
(\mathrm{mg} / 100 \mathrm{ml})\end{array}$ & $\begin{array}{c}\text { Sperm motility } \\
(\%)\end{array}$ & $\begin{array}{c}\text { No. of } \\
\text { men }\end{array}$ & $\begin{array}{c}\text { GPC } \\
(\mathrm{mg} / 100 \mathrm{ml})\end{array}$ \\
\hline 0 (azoospermia) & 78 & $110 \cdot 39 \pm 5 \cdot 27$ & 0 (necrospermia) & 6 & $128.7 \pm 6.58$ \\
$<20$ & 51 & $145 \cdot 22 \pm 7 \cdot 74^{* *}$ & $<20$ & 26 & $141.4 \pm 14.44$ \\
$20-40$ & 35 & $170.91 \pm 10 \cdot 43^{* *}$ & $20-40$ & 31 & $174.0 \pm 13 \cdot 66$ \\
$>40$ & 69 & $205.95 \pm 10 \cdot 37^{* *}$ & $>40$ & 85 & $196.3 \pm 8.35^{*}$ \\
\hline
\end{tabular}

Values are mean \pm s.e.m.

Values significantly different from values for azoospermic or necrospermic samples, ${ }^{*} P<0.05,{ }^{* *} P<0.001$ (Student's $t$ test).

Table 2. GPC concentrations (mean \pm s.e.m.) in normal and astheno-normospermic semen samples from men (all $>40 \times 10^{6} \mathrm{ml}$ spermatozoa $/ \mathrm{ml}$ )

\begin{tabular}{ccc}
\hline Semen samples & $\begin{array}{c}\text { No. of } \\
\text { samples }\end{array}$ & $\begin{array}{c}\mathrm{GPC} \\
(\mathrm{mg} / 100 \mathrm{ml})\end{array}$ \\
\hline $\begin{array}{c}\text { Normospermic, } \\
\text { motility }>40 \%\end{array}$ & 51 & $206.32 \pm 11.43$ \\
$\begin{array}{c}\text { Astheno-normospermic, } \\
\text { motility }<20 \%\end{array}$ & 12 & $109.86 \pm 15.47^{*}$ \\
\hline
\end{tabular}

* Significantly different from value for normospermic sample, $P<0.001$ (Student's $t$ test).

\section{Discussion}

The GPC values obtained for normal controls in this study are almost 2-3 times higher than those reported by other investigators (White, 1959). Repeated tests on the same samples and experiments to exclude possible interfering substances have led us to conclude that these differences may be attributed to inter-laboratory variation and the quality of reagents available.

The epididymis is known to be the major source of GPC in semen (Scott et al., 1963; Wallace et al., 1966; Calamera \& Lavieri, 1974). Masaki, Tomizuka \& Mouri (1966) have shown that the degree of GPC secretion varies proportionately with the number of spermatozoa and is increased with transit of spermatozoa through the epididymis in domestic animals. The present study also showed a significant increase in the seminal plasma GPC levels with increasing sperm density in man. Paz, Soffer, Homonnai \& Kraicer (1977), however, could not show a significant correlation between the biological properties of ejaculated spermatozoa and GPC. The spermatozoa per se have been shown to contribute only to a negligible extent to the total GPC concentration in semen (Frenkel et al., 1974). 
The physiological role of GPC in epididymal secretions is still unknown, but it has been suggested that metabolic and physical activities of spermatozoa (e.g. respiration and motility) are significantly affected by GPC and/or phospholipids (Hartree \& Mann, 1960; Masaki \& Tomizuka, 1965, 1966). Hirao (1975), while endorsing these suggestions, has assigned an important role to the levels of GPC as an index of fertility. Our findings for asthenonormospermic samples in which significantly reduced GPC levels were observed seem to support this view. In such cases, the spermatogenic function may be normal, as indicated by the satisfactory sperm count, and the fault may lie in the epididymis. All these patients remained infertile in spite of adequate fertility measures.

We thank the Dean, Dr J. V. Bhatt, T. N. Medical College and B. Y. L. Nair Charitable Hospital for allowing the publication of hospital data.

\section{References}

Calamera, J.C. \& Lavieri, J.C. (1974) Glycerylphosphorylcholine in human seminal plasma of normal subjects and sterile patients. Andrologia 6, $67-70$.

Dawson, R.M.C. \& Rowlands, I.W. (1959) Glycerylphosphorylcholine in male reproductive organs of rats and guinea-pigs. Q. Jl exp. Physiol. 44, 26-34.

Dawson, R.M.C., Mann, T. \& White, I.G. (1957) Glycerylphosphorylcholine and phosphorylcholine in semen and their relation to choline. Biochem. J. 65, 627-634.

Eliasson, R. (1971) Standards of investigation of human semen. Andrologia 3, 49-64.

Frenkel, G., Peterson, R.N., Davis, J.E. \& Freund, M. (1974) Glycerylphosphorylcholine and carnitine in normal human semen and in postvasectomy semen: differences in concentration. Fert. Steril. 25, 84-87.

Hartree, E.F. \& Mann, T. (1960) Phospholipids in mammalian semen. J. Reprod. Fert. 1, 23-29.

Hirao, K. (1975) A multiple regression analysis of six measurements of bovine semen characteristics for fertility. Int. J. Fert. 20, 204-208.

Masaki, J. \& Tomizuka, T. (1965) Change in phospholipid content of spermatozoa during maturation and ageing. 1. Effect of frequency of collection on plasmalogen content of bull and goat spermatozoa. Bull. natn. Inst. Anim. Ind. Jap. 9, 53-57.

Masaki, J. \& Tomizuka, T. (1966) Seasonal variations in the content of sperm phospholipid and seminal glycerylphosphorylcholine in bull semen. Bull. natn. Inst. Anim. Ind. Jap. 12, 33-42.

Masaki, J., Tomizuka, T. \& Mouri, H. (1966) Effects of glycerol and phosphoglycerol on the respiration and motility of spermatozoa in domestic animals. Jap. J. Anim. Reprod. 12, 100-104.

Paz, G., Soffer, A., Homonnai, T. \& Kraicer, P. (1977) Human semen analysis: seminal plasma and prostatic fluid composition and their interrelation with sperm quality. Int. J. Fert. 22, 140-147.

Scott, T.W., Wales, R.G., Wallace, J.C. \& White, I.G. (1963) Composition of ram epididymal and testicular fluid and the biosynthesis of glycerylphosphorylcholine by rabbit epididymis. J. Reprod. Fert. 6, 49-59.

Wallace, J.C., Wales, R.G. \& White, I.G. (1966) Respiration of rabbit epididymis and its synthesis of glycerylphosphorylcholine. Aust. J. biol. Sci. 19, 849-856.

White, I.G. (1959) Studies on estimation of glycerol, fructose and lactic acid with particular reference to semen. Aust. J. exp. Biol. 37, 441-450.

Received 1 February 1982 